\title{
Consumption of non-nutritive sweeteners and nutritional status in 10-16 year old students
}

\author{
Samuel Durán Agüero ${ }^{a}$, M.D., Gloria Oñate , M.D., and Pablo Haro Riverac , M.D.
}

\begin{abstract}
Introduction. The impact of non-nutritive sweeteners (NNS) on energy intake and body weight is not clear although they provide no energy compared to sucrose.

Objective. To establish if there are differences in the consumption of NNS as per the nutritional status and its association with overweight.

Population, Material and Methods. Crosssectional study including 571 male and female students aged 10-16 years old from the cities of Viña del Mar and Santiago de Chile who were administered an adapted food survey using pictures of NNS-containing products; nutritional status was assessed and students with overweight and obesity were categorized as a the overweight group.

Results. Of all surveyed students, $96.6 \%$ consume NNS on a daily basis. The comparison between the total NNS intake by nutritional status showed that male students in the overweight group consume more sucralose $(p<0.05)$ and saccharin $(p<0.01)$, while the comparison of NNS intake per kilogram of body weight showed that NNS consumption was higher in the overweight group $(p<0.05)$. Among female students, the normal weight group showed a higher consumption of acesulfame K per kilogram of body weight than the overweight group $(p<0.05)$. No association was observed in the studied sample between the overall NNS intake and obesity.

Conclusion. Of all surveyed students, $96.6 \%$ consume NNS on a daily basis, and no association was found between NNS consumption and overweight.

Key words: non-nutritive sweeteners, nutritional status, students, overweight.
\end{abstract}

http:/ / dx.doi.org/10.5546/aap.2014.eng.207

\section{INTRODUCTION}

From an epidemiological standpoint, the consumption of sugar-sweetened beverages is related to a positive energy balance and obesity incidence. Several reports have indicated that the consumption of sugar-sweetened beverages is positively correlated to a high body weight and a higher incidence of metabolic syndrome, type 2 diabetes, hypertension and heart diseases. ${ }^{1,2}$

As per the data published in 2007 by the Calorie Control Council (an international association representing the low- and reduced-calorie food and beverage industry), approximately 194 million people in the United States (around $64 \%$ of the total population) consumed diet food and beverages, reduced-calorie desserts and sugar substitutes. When comparing this information with the approximately 78 million people who consumed these products in 1986, it can be said that consumption has doubled over the past years (Calorie Control Council, 2009). ${ }^{3}$ A similar increase has been observed in Latin America, as demonstrated by the studies conducted by Cagnasso, et al. ${ }^{4}$ in Argentina, by Durán, et al. ${ }^{5}$ in Chile, and by Zanini, et al. ${ }^{6}$ in Brazil.

Non-nutritive sweeteners (NNS) first appeared in the late $19^{\text {th }}$ century, when saccharin was discovered by chance. At present, there are five NNS approved by the United States Food and Drug Administration (FDA): acesulfame $\mathrm{k}$, aspartame, saccharin, sucralose, and a plant-derived caloriefree sugar substitute (stevia), which has been declared safe by the FDA.

Overweight and obesity are influenced by genetic and environmental factors, such as ethnic origin, age, diet, level of physical activity, and psychosocial factors. ${ }^{7}$ Until recently, the general belief was that NNS may help to promote a healthy diet by providing a sweet taste with no calories or glycemic effects. The impact of NNS on energy intake, diet quality and body weight is not clear, although they provide no energy compared to sucrose.

Investigators have concluded that, in general, observational studies have not provided significant evidence to establish an association between NNS consumption and weight gain, although data are controversial. ${ }^{8}$ There is no evidence on such association among children and adolescents. 
The objective of this study is to establish if there are differences in the consumption of NNS as per the nutritional status and its association with obesity.

\section{POPULATION AND METHODS}

Cross-sectional study; 12 schools (eight municipal institutions and four subsidized schools) were randomly selected from the cities of Santiago and Viña del Mar, Chile. These schools account for $1.2 \%$ of all enrolled students in both cities. The sample size was estimated based on the study by Arcella, et al., ${ }^{9}$ with a 95\% confidence interval, a $90 \%$ power and a precision estimated as observed mean of usual aspartame consumption-daily admitted aspartame intake; data were analyzed using Excel. To this end, the type and content of each product's sweetener(s) were considered. Content was established based on the declaration of food additives by $100 \mathrm{~g}$ or $100 \mathrm{~mL}$ as indicated in the nutrition facts label. A survey on weekly food consumption was adapted (to include only those foods that contain sweeteners) and validated for the assessment of sweetener intake. ${ }^{5}$ Serving sizes were described using home measuring elements (cup, glass, spoon, teaspoon, plate, etc.). This information was used to estimate the daily intake for each NNS.

\section{Anthropometry}

An anthropometry was performed in each school by Nutrition students, who had received a standardized training. Students were assessed in their underwear and barefoot. Weight and height were measured using an electronic precision scale (GAMMA®) with an $0.1 \mathrm{~kg}$ sensitivity and a set square with an $0.5 \mathrm{~cm}$ sensitivity attached to the wall (using the Frankfurt plane methodology). The nutritional assessment was performed using the BMI/age correlation, as recommended by the United States Centers for Disease Control.

$$
n=\frac{\left(\mathrm{z}_{\alpha / 2}+\mathrm{z}_{\beta}\right)^{2} \mathrm{~S}^{2}}{\mathrm{~d}^{2}}=\frac{(1.96+1.28)^{2} \times 0.06^{2}}{(0.039-40)^{2}}=1
$$

Lastly, it was suggested that at least 20 students should be randomly assessed at each school.

The inclusion criterion was being a regular student aged 10 to 16 years old; exclusion criteria were being a student with metabolic conditions (phenylketonuria), type 1 diabetes, or not having completed the forms. No student refused to take part.

The protocol was reviewed and approved by the corresponding universities; parents were asked to sign a consent and students gave their assent for the assessment.

\section{PROCEDURES}

\section{Surveys}

In order to establish a sample of foods containing artificial sweeteners in the Chilean market, visits were made to the supermarkets of both cities; a total of 144 products were found. Each product was photographed and a set of pictures was prepared assigning a number to each product. Surveys were administered to school children by Nutrition students (CDC).

\section{Statistical Analysis}

Data were processed using an Excel sheet and the SPSS 19.0 statistical software. The normality of continuous outcome measures (age, weight, height, intake) was assessed using Shapiro-Wilk's goodness-of-fit test. Normal outcome measures were assessed using Student's t test, while not normal outcome measures were assessed using the Mann-Whitney U test. Correlations with a normal distribution were analyzed using Pearson's test, while correlations with not normal distribution were analyzed using Spearman's test. In addition, a logistic regression analysis was performed to assess the association between the consumption of sweeteners and the nutritional status following the adjustment for age and sex. In all cases, a value of $p<0.05$ was considered significant.

\section{RESULTS}

The studied sample included 571 male and female students from public and subsidized schools located in the cities of Viña del Mar and Santiago de Chile. Their average age, weight and height were $13.2 \pm 6.3$ years old, $53.9 \pm 12.4 \mathrm{~kg}$, and $1.52 \pm 0.1 \mathrm{~m}$, respectively. In this sample, $50 \%$ had a normal nutritional status (BMI between p10 and $<$ p85), $34.5 \%$ were overweight (BMI between $\mathrm{p} 85$ and $<$ p95), $11.8 \%$ were obese (BMI >p95: obesity) and $3.7 \%$ were underweight (BMI $<$ p10: low weight). Of all interviewed students, $96.6 \%$ indicated that they consume NNS on a regular basis.

The comparison of NNS consumption per kilogram of body weight by school course and sex (Table 1) indicated that there were no differences among courses. However, differences were found between male and females students in the overall group, with girls showing a significantly higher consumption of saccharin $(p<0.01)$.

The comparison of NNS consumption by nutritional status (Table 2), and considering both the normal weight group (slim and normal weight students) and the overweight group 
(overweight and obese students), showed that male students in the overweight group have a higher overall consumption of NNS, particularly sucralose $(p<0.05)$ and saccharin $(p<0.01)$. However, differences were observed when assessing NNS intake per kilogram of body weight: a higher consumption of saccharin in the overweight group $(p<0.05)$ and of acesulfame $\mathrm{k}$ in the normal weight group $(p<0.05)$. On the contrary, among female

TABLE 1. Comparison of sweeteners consumption per kilogram of body weight by sex and by school course

\begin{tabular}{|c|c|c|c|}
\hline & Male students $(n=281)$ & Female students $(n=290)$ & p value \\
\hline \multicolumn{4}{|c|}{ Fifth grade of basic/primary education } \\
\hline Sucralose & $1.95 \pm 1.97$ & $2.07 \pm 2.18$ & 0.601 \\
\hline Aspartame & $3.54 \pm 3.39$ & $3.30 \pm 2.90$ & 0.464 \\
\hline Cyclamate & $0.09 \pm 0.48$ & $0.08 \pm 0.35$ & 0.846 \\
\hline Saccharin & $0.36 \pm 0.82$ & $0.65 \pm 1.13$ & 0.006 \\
\hline Acesulfame k & $0.07 \pm 0.08$ & $0.06 \pm 0.06$ & 0.429 \\
\hline \multicolumn{4}{|c|}{ Sixth grade of basic/primary education } \\
\hline Sucralose & $1.63 \pm 1.28$ & $1.90 \pm 2.15$ & 0.726 \\
\hline Aspartame & $2.10 \pm 1.72$ & $3.82 \pm 3.85$ & 0.209 \\
\hline Cyclamate & $0.00 \pm 0.00$ & $0.14 \pm 0.59$ & 0.499 \\
\hline Saccharin & $1.37 \pm 0.69$ & $1.64 \pm 1.76$ & 0.661 \\
\hline Acesulfame $\mathrm{k}$ & $0.04 \pm 0.03$ & $0.07 \pm 0.07$ & 0.244 \\
\hline \multicolumn{4}{|c|}{ Seventh grade of basic/primary education } \\
\hline Sucralose & $1.25 \pm 1.00$ & $1.17 \pm 1.19$ & 0.832 \\
\hline Aspartame & $1.40 \pm 1.59$ & $1.52 \pm 1.45$ & 0.812 \\
\hline Cyclamate & $0.07 \pm 0.20$ & $0.00 \pm 0.00$ & 0.121 \\
\hline Saccharin & $1.08 \pm 1.29$ & $1.00 \pm 0.88$ & 0.804 \\
\hline Acesulfame $\mathrm{k}$ & $0.02 \pm 0.03$ & $0.02 \pm 0.03$ & 0.817 \\
\hline \multicolumn{4}{|c|}{ Eight grade of basic education/first year of secondary education } \\
\hline Sucralose & $1.33 \pm 1.41$ & $2.63 \pm 2.87$ & 0.393 \\
\hline Aspartame & $5.58 \pm 2.69$ & $3.41 \pm 3.26$ & 0.226 \\
\hline Cyclamate & $0.00 \pm 0.00$ & $0.11 \pm 0.42$ & 0.605 \\
\hline Saccharin & $2.14 \pm 2.09$ & $1.57 \pm 1.39$ & 0.495 \\
\hline Acesulfame k & $0.10 \pm 0.06$ & $0.07 \pm 0.07$ & 0.417 \\
\hline \multicolumn{4}{|c|}{ First year of middle school/second year of secondary education } \\
\hline Sucralose & $2.10 \pm 2.20$ & $2.20 \pm 2.30$ & 0.316 \\
\hline Aspartame & $4.12 \pm 3.01$ & $3.55 \pm 2.12$ & 0.442 \\
\hline Cyclamate & $0.02 \pm 0.07$ & $0.01 \pm 0.06$ & 0.952 \\
\hline Saccharin & $0.02 \pm 0.05$ & $0.02 \pm 0.36$ & 0.858 \\
\hline Acesulfame k & $0.07 \pm 0.06$ & $0.06 \pm 0.04$ & 0.540 \\
\hline \multicolumn{4}{|c|}{ Second year of middle school/third year of secondary education } \\
\hline Sucralose & $2.59 \pm 2.30$ & $2.62 \pm 2.34$ & 0.968 \\
\hline Aspartame & $5.22 \pm 4.62$ & $4.17 \pm 3.24$ & 0.330 \\
\hline Cyclamate & $0.25 \pm 0.93$ & $0.11 \pm 0.49$ & 0.502 \\
\hline Saccharin & $0.01 \pm 0.04$ & $0.01 \pm 0.03$ & 0.842 \\
\hline Acesulfame k & $0.11 \pm 0.11$ & $0.08 \pm 0.07$ & 0.381 \\
\hline \multicolumn{4}{|c|}{ Third year of middle school/fourth year of secondary education } \\
\hline Sucralose & $2.15 \pm 2.28$ & $1.86 \pm 1.95$ & 0.756 \\
\hline Aspartame & $1.48 \pm 1.87$ & $3.19 \pm 2.94$ & 0.131 \\
\hline Cyclamate & $0.00 \pm 0.01$ & $0.07 \pm 0.15$ & 0.226 \\
\hline Saccharin & $0.00 \pm 0.00$ & $0.00 \pm 0.00$ & 0.249 \\
\hline Acesulfame $\mathrm{k}$ & $0.03 \pm 0.03$ & $0.06 \pm 0.06$ & 0.227 \\
\hline \multicolumn{4}{|c|}{ Fourth year of middle school/fifth year of secondary education } \\
\hline Sucralose & $1.93 \pm 1.91$ & $1.66 \pm 1.29$ & 0.517 \\
\hline Aspartame & $3.38 \pm 2.77$ & $4.10 \pm 2.64$ & 0.295 \\
\hline Cyclamate & $0.08 \pm 0.23$ & $0.10 \pm 0.29$ & 0.809 \\
\hline Saccharin & $0.02 \pm 0.05$ & $0.02 \pm 0.06$ & 0.605 \\
\hline Acesulfame k & $0.07 \pm 0.07$ & $0.07 \pm 0.05$ & 0.626 \\
\hline
\end{tabular}

Student's $\mathrm{t}$ test. values expressed using mean $\pm \mathrm{SD}$. 
students, differences were only observed in the consumption of acesulfame k per kilogram of body weight: the normal weight group evidenced a significantly higher consumption than the overweight group $(p<0.05)$.

No significant correlations were found among male students when correlating the consumption of NNS (Figure 1), nutritional status and age. However, a positive correlation was observed among female students in relation to saccharin and sucralose intake in the overweight group and in relation to sucralose and aspartame in the normal weight group.

A positive correlation was observed in normal weight female students when correlating BMI and aspartame. Lastly, a positive correlation was also found between saccharin and acesulfame $\mathrm{k}$ intake when correlating consumption and age.

Table 3 shows the results of the multiple logistic regression test performed to assess the dependent outcome measure "nutritional status", nonadjusted data and data adjusted for age and sex. No significant differences were found with no intake of NNS in relation to the assessed predictive outcome measures.

\section{DISCUSSION}

The primary result observed is a higher NNS intake among male overweight students. However, in relation to girls, the consumption of NNS was higher among those with normal weight. In addition, it was observed that they consume more acesulfame $\mathrm{k}$ and saccharin as they get older. Lastly, no association was observed in the studied sample between NNS intake and overweight.

In this study, a high consumption of NNS was observed and found to be similar to a previous Chilean study. ${ }^{5}$ It is worth noting that each NNS intake was within the limits allowed for this

TABLE 2. Comparison of consumption of sweeteners by nutritional status

\begin{tabular}{|c|c|c|c|c|c|c|}
\hline & \multicolumn{3}{|c|}{ Male students } & \multicolumn{3}{|c|}{ Female students } \\
\hline & Normal weight & Overweight & p value & Normal weight & Overweight & p value \\
\hline Sucralose T & $82.8 \pm 60.5$ & $115.2 \pm 120.1$ & 0.024 & $106.7 \pm 105.9$ & $107.9 \pm 121.8$ & 0.944 \\
\hline Aspartame T & $185.3 \pm 140.3$ & $192.2 \pm 209.3$ & 0.798 & $176.2 \pm 138.2$ & $164.1 \pm 153.9$ & 0.582 \\
\hline Cyclamate T & $4.6 \pm 22.6$ & $2.9 \pm 8.1$ & 0.517 & $3.9 \pm 13.9$ & $5.2 \pm 22.9$ & 0.522 \\
\hline Saccharin $\mathrm{T}$ & $10.4 \pm 30.8$ & $31.1 \pm 57.5$ & 0.003 & $31.4 \pm 52.6$ & $37.2 \pm 61.8$ & 0.503 \\
\hline Acesulfame k T & $54.0 \pm 49.1$ & $53.6 \pm 96.7$ & 0.974 & $42.2 \pm 38.8$ & $58.8 \pm 51.3$ & 0.683 \\
\hline Sucralose k/bw & $1.8 \pm 1.5$ & $2.0 \pm 2.3$ & 0.395 & $2.1 \pm 2.1$ & $1.9 \pm 2.2$ & 0.423 \\
\hline Aspartame k/bw & $3.7 \pm 3.0$ & $3.2 \pm 3.7$ & 0.331 & $3.6 \pm 2.9$ & $2.9 \pm 2.8$ & 0.101 \\
\hline Cyclamate k/bw & $0.1 \pm 0.6$ & $0.2 \pm 0.7$ & 0.297 & $0.07 \pm 0.32$ & $0.09 \pm 0.38$ & 0.794 \\
\hline Saccharin k/bw & $0.2 \pm 0.7$ & $0.5 \pm 0.9$ & 0.029 & $0.65 \pm 1.10$ & $0.65 \pm 1.18$ & 0.996 \\
\hline Acesulfame k k/bw & $0.08 \pm 0.08$ & $0.05 \pm 0.07$ & 0.040 & $0.07 \pm 0.06$ & $0.05 \pm 0.05$ & 0.015 \\
\hline
\end{tabular}

Student's t test, values expressed using mean \pm SD. $T=$ total intake; $k / b w=$ kilogram of body weight.

TABLE 3. Association between consumption of different sweeteners and overweight-obesity

\begin{tabular}{|c|c|c|c|c|}
\hline \multirow{2}{*}{$\frac{\text { Outcome measures }}{\text { Aspartame consumption }}$} & \multirow{2}{*}{$\begin{array}{c}\text { OR } \\
0.770\end{array}$} & \multicolumn{2}{|c|}{$95 \%$ CI } & \multirow{2}{*}{$\frac{\mathbf{p} \text { value }}{0.592}$} \\
\hline & & 0.297 & 2.000 & \\
\hline Aspartame consumption* & 1.450 & 0.512 & 4.106 & 0.484 \\
\hline Cyclamate consumption & 0.755 & 0.509 & 1.119 & 0.162 \\
\hline Cyclamate consumption* & 1.147 & 0.749 & 1.754 & 0.529 \\
\hline Saccharin consumption & 0.988 & 0.654 & 1.920 & 0.174 \\
\hline Saccharin consumption* & 0.852 & 0.573 & 1.269 & 0.431 \\
\hline Acesulfame $\mathrm{k}$ consumption & 0.713 & 0.104 & 4.869 & 0.730 \\
\hline Acesulfame k consumption* & 1.125 & 0.734 & 1.635 & 0.543 \\
\hline Total consumption of NNS & 0.712 & 0.164 & 4.969 & 0.723 \\
\hline Total consumption of NNS* & 1.433 & 0.501 & 3.182 & 0.501 \\
\hline
\end{tabular}

* Adjusted for age, education level and sex. 


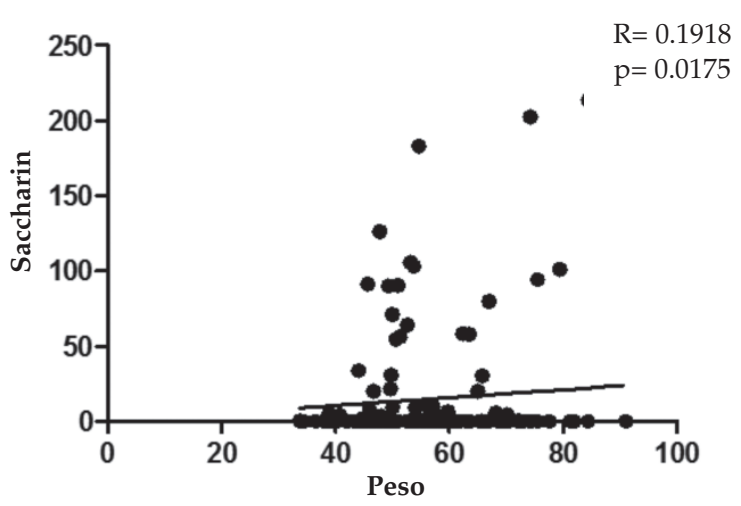

c.

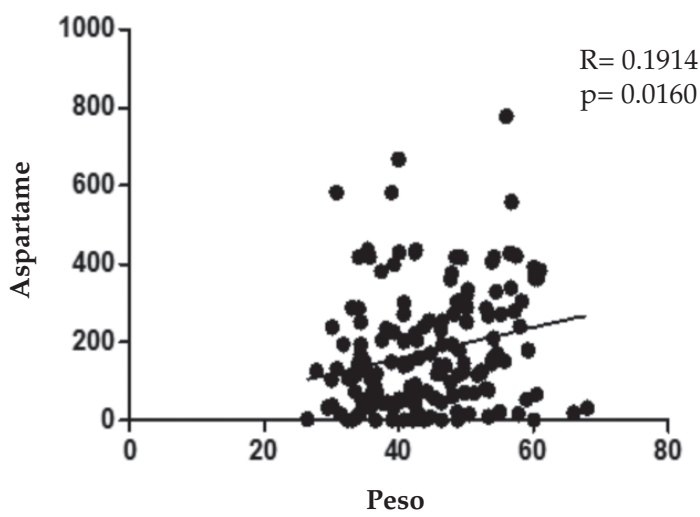

e.

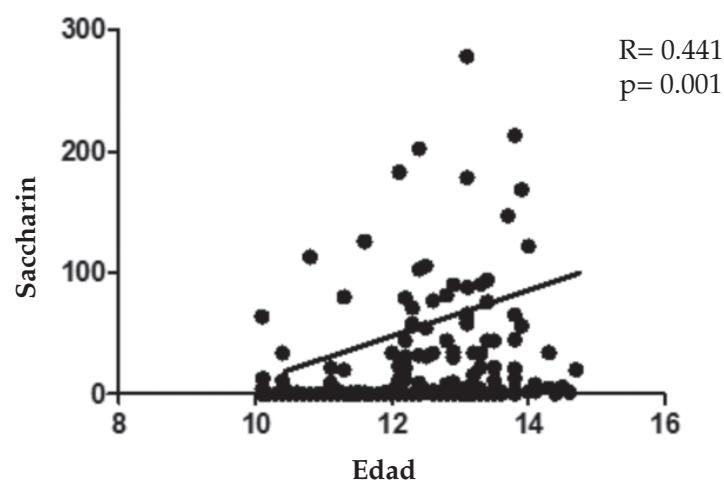

b.

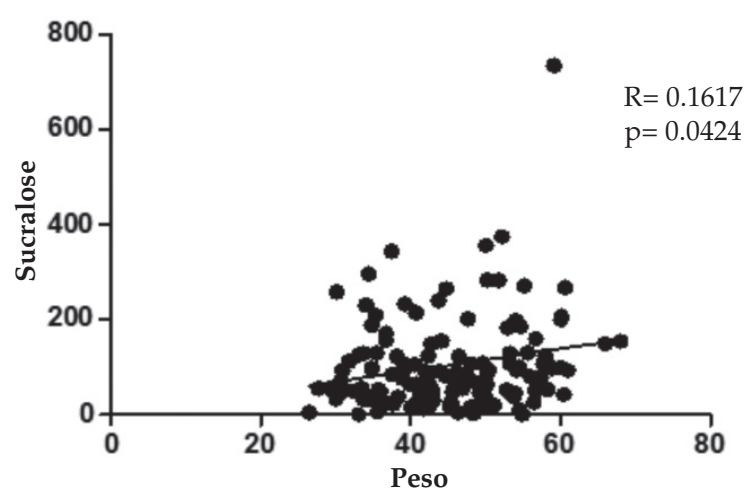

d.

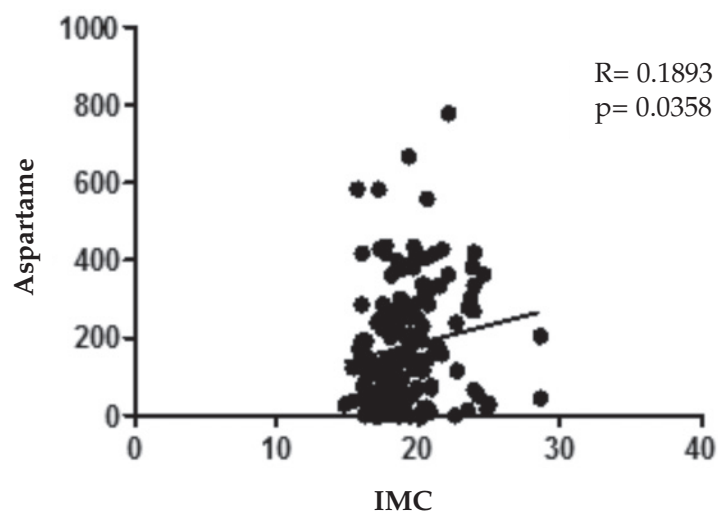

f.

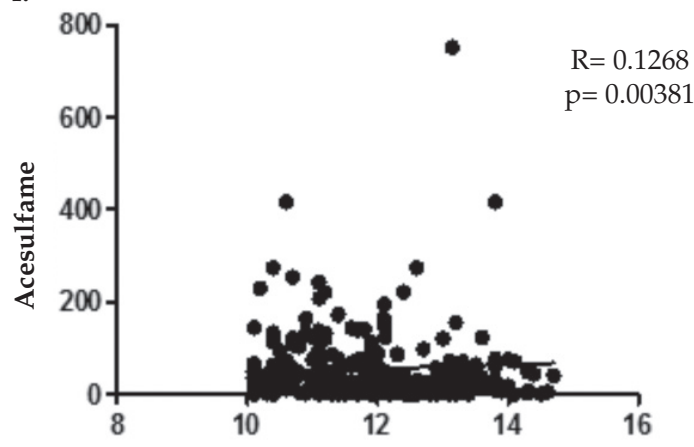

Edad

(a) Correlation between weight and saccharin consumption in overweight girls; (b) correlation between weight and sucralose consumption in normal weight girls; (c) correlation between weight and aspartame consumption in normal weight girls; (d) correlation between BMI and aspartame consumption in overweight girls; (e) correlation between age and saccharin consumption in girls; (f) correlation between age and acesulfame k consumption in girls. NNS: non nutritive sweeteners. 
population. Such elevated intake is mainly due to the large number of NNS-containing foods, especially low-priced soft drinks.

Some studies have proposed that NNS play a major role in weight control among children, adolescents and adults. However, a new hypothesis suggests that people may compensate the calories saved by using NNS with an increased appetite in the following meal, thus gaining weight. ${ }^{10}$ In contrast, the results of shortterm observational and experimental studies do not support this hypothesis.

An increasing number of epidemiological studies have reported that the consumption of NNS-containing products has a positive correlation with the incidence of obesity, weight gain, type 2 diabetes, heart diseases and other metabolic syndrome symptoms..$^{2,11,12}$ Such findings have encountered a strong resistance by the manufacturers and representatives of these products, who usually state that there is no viable mechanism to explain such results. ${ }^{13}$ This was the case of a recent report indicating that the consumption of diet sodas was associated with metabolic impairment and weight gain. ${ }^{14}$ Although it is possible that people who tend to gain weight use NNS as a strategy to reduce calorie intake, it is probable that a significant number of consumers currently use reduced or non-caloric foods and sugar-free beverages to fight against weight gain. ${ }^{7}$ Replacing a sugarsweetened beverage with a NNS-sweetened beverage will reduce calorie intake by approximately $150 \mathrm{kcal}$, and using NNS instead of two teaspoons of sugar ( $18 \mathrm{~g})$ for a cup of tea or coffee three times a day will save approximately 100 kcal a day. ${ }^{3}$

In the Framingham Heart Study, Dhingra, et al. ${ }^{15}$ reported a positive relation between the consumption of diet or regular sodas and the prevalence of metabolic syndrome. Similar results have been reported by independent studies conducted by Lutsey, et al. ${ }^{11}$ and by Nettleton, et al. ${ }^{14}$ Lastly, Fowler, et al. ${ }^{12}$ indicated that, in the case of subjects who had a normal weight or were not obese $(\mathrm{BMI}<30)$ at study initiation, drinking $>21$ NNS-sweetened beverages a week (diet sodas and artificial sweeteners in tea and coffee) was associated with almost twice the possibility of being overweight at follow-up seven or eight years later, compared to those who did not drink these beverages.

In addition, the results of short-term observational and experimental studies do not support this hypothesis.
It should be noted that this type of crosssectional study can only demonstrate associations, not causality.

In relation to the association among NNS consumption, energy and body weight, results have been controversial, particularly for aspartame. Most studies indicate that aspartame reduces food intake and may help to control weight. ${ }^{16}$ However, other studies paradoxically suggest that aspartame may increase appetite ${ }^{17}$ and therefore leads to weight gain. ${ }^{18}$ At present, there is no official recommendation on the use of NNS to control weight. ${ }^{19}$

Stevia has been related to increased insulin sensitivity in rodent models ${ }^{20}$ and has demonstrated beneficial effects on blood glucose and insulin levels in human studies. ${ }^{21}$ This suggests that stevia may have a role in food intake regulation.

A recent study by Anton, et al. ${ }^{20}$ concluded that participants who consumed aspartame or stevia compensated its consumption by eating more, either at lunch or dinner, when they had eaten low-calorie preloads compared to eating more caloric preloads that contained sucrose. Therefore, participants' overall calorie intake was lower when they consumed stevia or aspartame than when they had sucrose, only because of the varying calorie amounts of the preloads used in the study.

Prior studies demonstrated similar results and found that modifying the energy density of foods does not translate into a compensated energy consumption in the following meals. ${ }^{22}$

Consumption of preloads with stevia significantly reduced postprandial insulin levels compared to preloads with aspartame and sucrose, while stevia also reduce postprandial glucose levels when compared to sucrose. Consumption of preloads containing aspartame also reduced postprandial glucose levels when compared to sucrose less than twenty minutes after eating the preload. ${ }^{20}$

Studies conducted on animal models show that rats with a NNS-sweetened diet have a higher weight, increased fat accumulation and a weaker thermic effect in response to food intake. ${ }^{19}$ Other recent study supports the hypothesis that NNS alter the energy balance and demonstrated that rats that receive stevia-sweetened liquids weight more than those who drink glucosesweetened liquids. ${ }^{17}$ One of the mechanisms that may establish an association between NNS and weight gain is that NNS could alter the gut microbiota. It has been demonstrated that gut microbiota alterations can lead to inflammatory 
processes that promote insulin resistance, fat accumulation and increased body weight in the host. ${ }^{23,24}$ This was proven in a study on rats fed with maltodextrin and sucralose or maltodextrin mixed with sucralose and glucose for 12 weeks; after this period, significant alterations were observed in the gut flora, which was associated with weight gain. ${ }^{24}$

Other possible explanatory mechanism is caloric compensation, which takes place when animals adjust the amount of calories consumed at one time by reducing calorie intake in the following meals. ${ }^{25}$ Studies conducted on rats demonstrate that rats receiving saccharin-sweetened foods ate more during the following meal when compared to those that received glucose, and their overall energy intake was significantly higher, therefore indicating that the rats that consumed saccharin were less capable of reducing calorie intake than those fed with glucose. ${ }^{26}$

Other of the studied mechanisms to explain weight gain in rats is that, like glucose, NNS could also interact with sweet taste receptors, therefore modulating SGLT1 and GLUT 2 transporters and finally increasing nutrient absorption. Intestinal perfusion with NNS was performed in rats, which induced a rapid modulation of SGLT127 and increased apical GLUT 2 insertion. ${ }^{28}$

In healthy fasting adults, an acute intragastric infusion of sucralose did not stimulate insulin, incretins such as the glucagon-like peptide-1 (GLP1) or the release of glucose-dependent insulinotropic polypeptide (GIP), nor slowed gastric emptying. ${ }^{29}$ In addition, when sucralose, aspartame or acesulfame $\mathrm{k}$ are delivered intraduodenally, they do not have an effect on postprandial blood glucose levels, GLP-1 secretion or glucose absorption by the small intestine lumen. ${ }^{30,31}$

To date, only this last mechanism has been studied in humans. Data on humans and animals are contradictory, and it is not clear if NNS affect incretin response (GLP-1 and GIP) in vivo by means of the interaction of intestinal receptors for sweet taste. ${ }^{30,31}$

Some of this study's strengths are that using the frequency consumption survey provided information on the usual NNS intake among surveyed students and that the set of pictures allowed respondents to identify the corresponding NNS-containing foods. Some of this study's weaknesses are that the survey tends to overestimate intake and is based on respondents' recall, that it is difficult to establish serving sizes and, above all, that this is a cross-sectional study and, therefore, it is not possible to establish a causality, only an association.

\section{CONCLUSION}

In this study, a high consumption of NNS was observed; however, no association was found between NNS consumption and obesity, either with adjusted and not adjusted outcome measures. It is necessary to perform controlled, randomized trials to evaluate if there is a risk for weight gain in individuals who consume NNS given that its consumption has become massive, especially in the children and adolescent population.

\section{Acknowledgments}

To all Nutrition and Dietetics students who helped with the surveys, and to Estela Blanco, Epidemiologist, for reviewing the manuscript.

\section{REFERENCES}

1. Chen L, Appel LJ, Loria C, Lin PH, et al. Reduction in consumption of sugar-sweetened beverages is associated with weight loss: the PREMIER trial. Am J Clin Nutr 2009;89(5):1299-306.

2. Fung TT, MalikV, RexrodeKM,Manson JE, et al.Sweetened beverage consumption and risk of coronary heart disease in women. Am J Clin Nutr 2009;89(4):1037-42.

3. Patton J, Hubrich B, O'brien Nabors L. The benefits of reduced caloric foods and beverages in weightmanagement. En: O'brien Nabors L (Ed). Alternative Sweeteners. $4^{\text {th }}$ ed. Atlanta: CRC Press 2010:525-48.

4. Cagnasso C, LópezL, Valencia M. Edulcorantesnonutritivos en bebidas sin alcohol: estimación de la ingesta en niños y adolescentes. Arch Argent Pediatr 2007;105:517-21.

5. Durán S, Quijada M, Silva L, Almonacid N, et al. Niveles de ingesta diaria de edulcorantes no nutritivos en escolares de la región de Valparaíso. Rev Chil Nutr 2011;38:444-9.

6. Zanini R, Araújo C, Martínez-Mesa J. Utilização de adoçantes dietéticos entre adultos em Pelotas, Rio Grande do Sul, Brasil: um estudo de base populacional. Cad Saúde Pública 2011;27:924-34.

7. Hill JO. Can a small-changes approach help address the obesity epidemic? A report of the Joint Task Force of the American Society for Nutrition, Institute of Food Technologists, and International Food Information Council. Am J Clin Nutr 2009;89:477-84.

8. Butchko HH, Stargel WW, Comer CP, Mayhew DA, et al. Aspartame: review of safety. Regul Toxicol Pharmacol 2002;35:S1-93.

9. Arcella D, Le Donne C, Piccinelli R, Leclercq C. Dietary estimated intake of intense sweeteners by Italian teenagers. Present levels and projections derived from the INRANRM 2001 food survey. Food Chem Toxicol 2004;42:677-85.

10. Anderson GH. Nutritional and health aspects of macronutrient substitution. Ann N Y Acad Sci 1997;819:111.

11. Lutsey PL, Steffen LM, Stevens J. Dietary intake and the development of the metabolic syndrome: the Atherosclerosis Risk in Communities study. Circulation 2008;117(6):754-61.

12. FowlerSP,Williams K, ResendezRG,HuntKJ, et al. Fueling the obesity epidemic? Artificially sweetened beverage 
use and long-term weight gain. Obesity (Silver Spring) 2008;16(8):1894-900.

13. Doheny, K. Researchers Point Finger at Diet, RegularSodas; Industry Officials Disagree. WebMD. 2007. Available at: http://www.webmd.com/heart/metabolic-syndrome/ news / 20070723/1-daily-soda-may-boost-heartdisease.

14. Nettleton JA, Polak JF, Tracy R, Burke GL, et al. Dietary patterns and incident cardiovascular disease in the Multi-Ethnic Study of Atherosclerosis. Am J Clin Nutr 2009;90(3):647-54.

15. Dhingra R, Sullivan L, Jacques PF, Wang TJ, et al. Soft drink consumption and risk of developing cardiometabolic risk factors and the metabolic syndrome in middle-aged adults in the community. Circulation 2007;116(5):480-8.

16. De la Hunty A, Gibson S, Ashwell M. A review of the effectiveness of aspartame in helping with weightcontrol. British Nutr Found Nutr Bull 2006;31:115-28.

17. Swithers SE, Martin AA, Davidson TL. High-intensity sweeteners and energy balance. Physiol Behav 2010;100:55-62.

18. Blundell JE, Hill AJ. Paradoxical effects of an intense sweetener (aspartame) on appetite. Lancet 1986;1:1092-3.

19. Swithers SE, Davidson TL. A role for sweet taste: calorie predictive relations in energy regulation byrats. Behav Neurosci 2008;122:161-73.

20. Anton SD, Martin CK, Han H, Coulon S, et al. Effects of stevia, aspartame, and sucrose on food intake, satiety, and postprandial glucose and insulin levels. Appetite 2010;55(1):37-43.

21. Chang JC, Wu MC, Liu IM, Cheng JT. Increase of insulin sensitivity by stevioside in fructose-rich chow-fed rats. Horm Metab Res 2005;37(10):610-6.

22. Rolls BJ, Laster LJ, Summerfelt A. Hunger and food intake following consumption of low calorie foods. Appetite 1989;13:115-27.
23. Vijay-Kumar M, Aitken JD, Carvalho FA, Cullender TC, et al. Metabolic syndrome and altered gut microbiota in mice lacking Toll-like receptor 5. Science 2010;328:228-31.

24. Abou-Donia MB, El-Masry EM, Abdel-Rahman AA, McLendon RE, Schiffman SS, et al. Splenda alters gut microflora and increases intestinal p-glycoprotein and cytochrome p-450 in male rats. J Toxicol Environ Health A 2008;71:1415-29.

25. Rowland NE, Nasrallah N, Robertson KL. Accurate caloric compensation in rats for electively consumed ethanol-beer or ethanol-polycose mixtures. Pharmacol Biochem Behav 2005;80(1):109-14.

26. Swithers SE, Baker CR, Davidson TL. General and persistent effects of high-intensity sweeteners on body weight gain and caloric compensation in rats. Behav Neurosci 2009;123:772-80.

27. Stearns AT, Balakrishnan A, Rhoads DB, Tavakkolizadeh A. Rapid upregulation of sodium-glucose transporter SGLT1 in response to intestinal sweet taste stimulation. Ann Surg 2010;251:865-71.

28. Mace OJ, AffleckJ,Patel N, Kellett GL. Sweet taste receptors in rat small intestine stimulate glucose absorption through apical GLUT2. J Physiol 2007;582:379-92.

29. Ma J, Bellon M, Wishart JM, Young R, et al. Effect of the artificial sweetener, sucralose, on gastric emptying and incretin hormone release in healthy subjects. Am J Physiol Gastrointest Liver Physiol 2009;296:G735-9.

30. Ma J, Chang J, Checklin HL, Young RL, et al. Effect of the artificial sweetener, sucralose, on small intestinal glucose absorption in healthy human subjects. Br J Nutr 2010;104:803-6.

31. Steinert RE, Frey F, Topfer A, Drewea J, et al. Effects of carbohydrate sugars and artificial sweeteners on appetite and the secretion of gastrointestinal satiety peptides. $\mathrm{Br} J$ Nutr 2011;105;1320-8. 